\title{
Perfilhamento do capim-piatã submetido a regimes de desfolhação intermitente
}

[Tillering of piatã grass subject intermittent cutting]

\author{
G.O. Rocha ${ }^{1}$, F.H.M. Chizzotti ${ }^{2}$, M.E.R. Santos ${ }^{3}$, \\ B.M.L. Sousa ${ }^{4}$, D.M. Fonseca ${ }^{2}$ \\ ${ }^{1}$ Aluno de pós-graduação - Universidade Federal de \\ Uberlândia - Uberlândia, MG \\ ${ }^{2}$ Universidade Federal de Viçosa - Viçosa, MG \\ ${ }^{3}$ Universidade Federal de Uberlândia - Uberlândia, MG \\ ${ }^{4}$ Universidade Federal de Sergipe - Aracaju, SE
}

\begin{abstract}
RESUMO
Objetivou-se avaliar o perfilhamento da Brachiaria brizantha cv. Piatã, como base para identificação das frequências e alturas pós-corte mais adequadas para essa gramínea forrageira. Em um esquema fatorial 2 × 2 , foram estudadas combinações entre duas frequências de corte $\left(95 \%\right.$ e máxima interceptação de luz, $\left.\mathrm{IL}_{\max }\right)$ e duas alturas pós-corte $(15$ e $20 \mathrm{~cm})$. O delineamento foi em blocos ao acaso, com três repetições, totalizando 12 unidades experimentais de $14 \mathrm{~m}^{2}$ cada. Foram avaliadas as taxas de aparecimento (TApP) e de mortalidade (TMoP) de perfilhos, o índice de estabilidade (IE) e a densidade populacional de perfilhos. A maior TApP no dossel sob IL de $95 \%$ ocorreu no Verão 1, em comparação às demais épocas. Nos dosséis manejados com $\mathrm{IL}_{\max }$, a TApP foi superior no Verão 1 e no Outono, quando comparados às outras épocas. No Verão 1 e no Final da Primavera e Verão 2, houve as maiores TMoP para as duas frequências de corte avaliadas. No Outono, a TMoP também foi alta no dossel cortado com $\mathrm{IL}_{\text {máx. }}$ O IE foi menor durante o Verão 1 no dossel sob $\mathrm{IL}_{\max } \mathrm{e}$ com $15 \mathrm{~cm}$ de resíduo $(0,995)$. Porém, nas demais épocas, os valores de índice de estabilidade foram maiores que uma unidade e não foram influenciados pela frequência e altura pós-corte. A densidade populacional de perfilhos foi menor no Verão 1, em comparação às demais épocas. O capim-piatã pode ser desfolhado com qualquer combinação entre as interceptações de luz, $95 \%$ e $\mathrm{IL}_{\max }$, e alturas pós-corte, 15 ou $20 \mathrm{~cm}$, sem prejudicar a persistência do pasto.
\end{abstract}

Palavras-chave: aparecimento de perfilho, interceptação de luz, índice de estabilidade, mortalidade de perfilho

\begin{abstract}
The aim of this study was to evaluate the tillering of Brachiaria brizantha $c v$. Piatã, as a basis for identifying the frequencies and post-cutting heights most suitable for this grass. In a $2 \times 2$ factorial scheme, combinations between two cut frequencies $\left(95 \%\right.$ and maximum light interception, $\left.I L_{\max }\right)$ and two post-cut heights $(15$ and $20 \mathrm{~cm})$ were studied. The experimental design was in randomized blocks with 3 replicates, totaling 12 experimental units of $14 \mathrm{~m}^{2}$ each. Rates of appearance (TAR) and mortality (TMR) of tillers, the stability index and the population density of tillers were evaluated. The highest TAR in the canopy under 95\% IL occurred in Summer 1, in comparison to the other seasons. In the canopies managed with $I L_{\text {max }}$, TAR was higher in summer 1 and in autumn, when compared to other seasons. In summer 1 and at the end of spring and summer 2, there were the highest TMR for the two cutoff frequencies evaluated. In autumn, TMR was also high in the canopy cut with $I L_{\max }$. IE was lower during summer 1 in the canopy under $I L_{\max }$ and $15 \mathrm{~cm}$ of residue (0.995). However, at other times, stability index values were greater than one unit and were not influenced by post-cut frequency and height. The population density of tillers was lower in Summer 1, when compared to the other seasons. The piata grass may be defoliated with any combination of light intercepts, 95\% and ILmax, and post-cut heights, 15 or $20 \mathrm{~cm}$, without impairing the persistence of pasture.
\end{abstract}

Keywords: tiller appearance, light interception, stability index, tiller death

Recebido em 27 de outubro de 2017

Aceito em 24 de janeiro de 2019

E-mail: gabriel.o.rocha@hotmail.com 


\section{INTRODUÇÃO}

O perfilhamento é um processo natural de reposição dos perfilhos mortos ao longo do ano, que possibilita a perenidade e produtividade da gramínea forrageira (Bullock, 1996), bem como garante a sua adaptação às diferentes condições de meio, incluindo o ambiente de desfolhação e as condições climáticas variáveis ao longo do ano (Sbrissia et al., 2010). Por isso, o número de perfilhos é característica frequentemente usada como indicadora da persistência e produtividade do pasto. $\mathrm{O}$ balanço entre o aparecimento e a mortalidade de perfilhos determina o número dessas unidades de crescimento no dossel forrageiro. A densidade populacional de perfilhos tem efeitos sobre a estrutura e a produção de forragem do pasto, fatores determinantes da produção animal em pastagens (Sbrissia; Silva, 2001, 2008).

A densidade populacional de perfilhos, juntamente com o tamanho e o número de folhas vivas por perfilho, determina o índice de área foliar do pasto, característica responsável pela interceptação de luz pelo dossel forrageiro, e, com efeito, influencia a produção de fotoassimilados e a produção de forragem (Sbrissia; Silva, 2001, 2008). Entre as características estruturais do pasto, o número de perfilhos é a variável mais flexível, sendo a maior responsável pela plasticidade fenotípica da gramínea forrageira, permitindo adaptação às diferentes estratégias de manejo da desfolhação, o que contribui para manter relativamente estável a capacidade produtiva do dossel (Sbrissia et al., 2010; Barbosa et al., 2007). Apesar de sua relevância, informações relacionadas à dinâmica de perfilhamento do capim-piatã manejado sob desfolhação intermitente são escassas na literatura científica, o que demonstra a necessidade de pesquisas nesta área. Assim, objetivou-se avaliar a dinâmica de perfilhamento e a densidade populacional de perfilhos do capim-piatã, como subsídio para a identificação das frequências e intensidades de corte mais apropriadas para essa gramínea forrageira.

\section{MATERIAL E MÉTODOS}

O experimento foi conduzido no Setor de Forragicultura da Universidade Federal de Viçosa, em Viçosa, MG (latitude $20^{\circ} 45^{\prime} \mathrm{S}$, longitude $42^{\circ} 51^{\prime} \mathrm{W}$ e altitude de $651 \mathrm{~m}$ ), no período de janeiro de 2012 a março de 2013. O clima da região é do tipo Cwa subtropical (Alvares et al., 2013), com duas estações do ano bem definidas, verão quente e chuvoso, e inverno frio e seco. Os dados climáticos do período experimental foram coletados em estação meteorológica, distante aproximadamente 1.000 metros do local do experimento (Fig. 1).

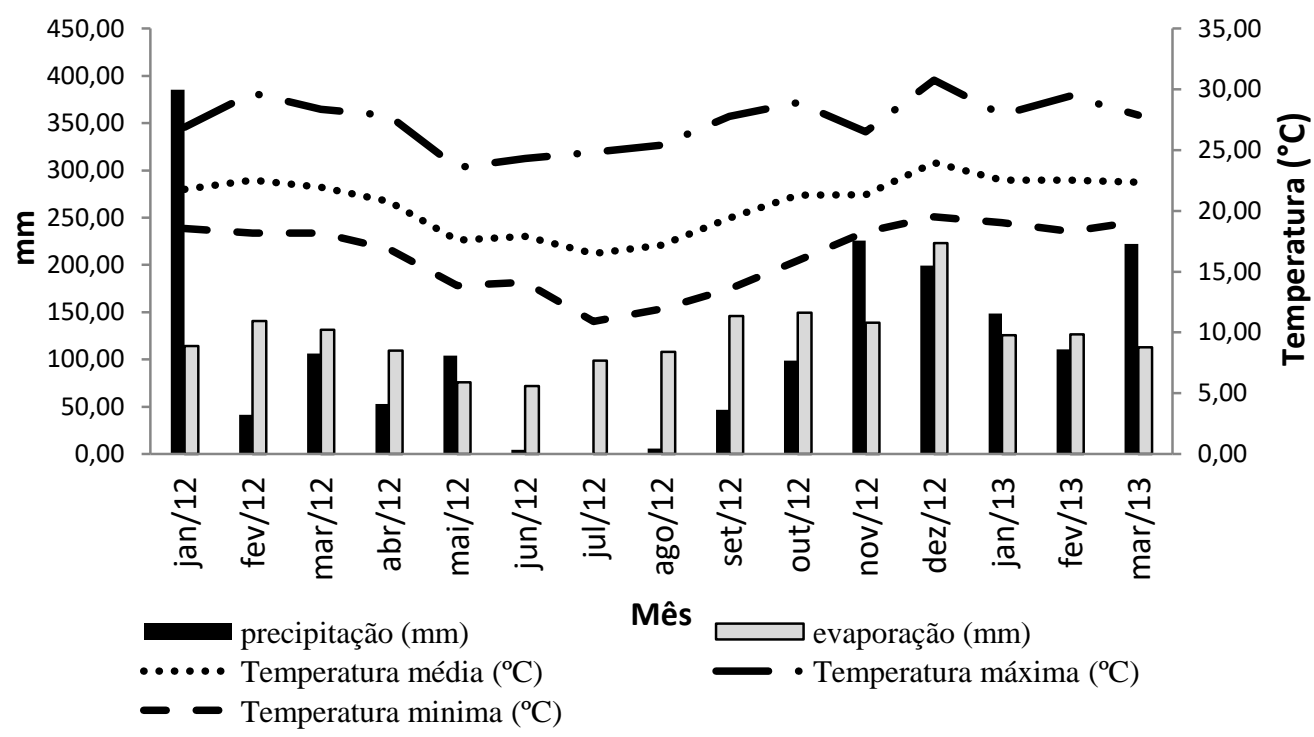

Figura 1. Precipitação pluviométrica e evaporação acumuladas mensais (mm), temperaturas mínima, média e máxima $\left({ }^{\circ} \mathrm{C}\right)$, durante o período experimental. 
O solo da área experimental é classificado como Argissolo Vermelho-Amarelo (Sistema..., 1999). No início do experimento, foram coletadas amostras de solo na profundidade de 0 a $20 \mathrm{~cm}$ para análise do nível de fertilidade. Os resultados foram: $\mathrm{pH}$ em $\mathrm{H}_{2} \mathrm{O}, 5,09 ; \mathrm{P}, 1,5 \mathrm{mg} \mathrm{dm}^{-3} ; \mathrm{K}$, $29 \mathrm{mg} \mathrm{dm}^{-3} ; \mathrm{Ca}^{+2}, 2,7 \mathrm{cmol}_{\mathrm{c}} \mathrm{dm}^{-3} ; \mathrm{Mg}^{+2}, 0,6 \mathrm{cmol}_{\mathrm{c}}$ $\mathrm{dm}^{-3} ; \mathrm{Al}^{+3}, 0,1 \mathrm{cmol}_{\mathrm{c}} \mathrm{dm}^{-3} ; \mathrm{H}+\mathrm{Al}, 5,5 \mathrm{cmol}_{\mathrm{c}} \mathrm{dm}^{-3}$; $\mathrm{SB}, 3,37 \mathrm{cmol}_{\mathrm{c}} \mathrm{dm}^{-3} ; \mathrm{t}, 3,47 \mathrm{cmol}_{\mathrm{c}} \mathrm{dm}^{-3} ; \mathrm{T}$, $8,87 \mathrm{cmol}_{\mathrm{c}} \mathrm{dm}^{-3} ; \mathrm{V}, 38 \%$; m, 29\%. Com base nesses resultados, as adubações foram realizadas seguindo as diretrizes do CFSEMG (Ribeiro et al., 1999) para um sistema de médio nível tecnológico. No dia 15 de janeiro de 2012, foi realizada uma única aplicação de $50 \mathrm{~kg} \mathrm{ha}^{-1}$ de $\mathrm{N}$, de $\mathrm{P}_{2} \mathrm{O}_{5}$ e de $\mathrm{K}_{2} \mathrm{O}$, na forma de sulfato de amônio, superfosfato simples e cloreto de potássio, respectivamente. Adicionalmente, $150 \mathrm{~kg} \mathrm{ha}^{-1}$ de $\mathrm{N}$ foram aplicados entre janeiro e março de 2012, de forma parcelada e em quantidade proporcional ao período de descanso, sempre após os cortes dos dosséis.

Em 06 de outubro de 2012, foram aplicados $15 \mathrm{~kg}$ ha $^{-1}$ de $\mathrm{P}_{2} \mathrm{O}_{5}, 60 \mathrm{~kg} \mathrm{ha}^{-1}$ de $\mathrm{K}_{2} \mathrm{O}$ e $60 \mathrm{~kg} \mathrm{ha}^{-1}$ de $\mathrm{N}$, na forma de adubo formulado 20-05-20 (20\% de $\mathrm{N}, 5 \%$ de $\mathrm{P}_{2} \mathrm{O}_{5}$ e $20 \%$ de $\mathrm{K}_{2} \mathrm{O}$ ). Adicionalmente, mais $150 \mathrm{~kg} \mathrm{ha}^{-1}$ de $\mathrm{N}$ foram distribuídos às parcelas entre outubro de 2012 e março de 2013, de forma semelhante à adubação descrita no verão anterior. A espécie forrageira avaliada foi a Brachiaria brizantha cv. Piatã, estabelecida em 2007. O dossel forrageiro estava em crescimento livre por seis meses antes da demarcação das unidades experimentais, que ocorreu em 13 de janeiro de 2012. Nesta data, foi realizado o corte, com roçadeira costal, das plantas nas alturas almejadas.

Foram avaliadas combinações de duas condições de pré-corte (95\% e máxima interceptação de luz pelo dossel, IL) e duas condições de pós-corte (alturas residuais, AR, de 15 ou $20 \mathrm{~cm}$ ) em um arranjo fatorial $2 \times 2$, correspondendo a quatro regimes de desfolhação: 95/15 (95\% de IL e AR de $15 \mathrm{~cm}), 95 / 20$ (95\% de IL e AR de $20 \mathrm{~cm})$, $\mathrm{IL}_{\max } / 15$ (Máxima IL e AR de $15 \mathrm{~cm}$ ) e $\mathrm{IL}_{\max } / 20$ (Máxima IL e AR de $20 \mathrm{~cm}$ ). O delineamento foi em blocos ao acaso, com três repetições, perfazendo 12 unidades experimentais de $14 \mathrm{~m}^{2}$ $(4,0 \times 3,5 \mathrm{~m})$.

O dossel foi cortado quando as metas de précorte de interceptação luminosa foram alcançadas. Para isso, foi usada uma roçadeira costal e uma régua graduada. O acompanhamento do nível de interceptação de luz pelo dossel foi realizado utilizando-se o analisador de dossel LAI-2000 da LI-COR ${ }^{\circledR}$ (LICOR, Linconln, Nebraska, EUA). O monitoramento da IL pelo dossel foi realizado no pós-corte, semanalmente, durante a rebrotação dos pastos até a IL de $90 \%$. A partir desse ponto, a mensuração da IL ocorreu a cada dois dias, até que as metas de 95 e máxima IL fossem atingidas. A IL foi considerada máxima quando seu valor não aumentou após três medições consecutivas. As medições foram efetuadas em duas estações por unidade experimental, cada estação correspondendo a uma leitura em um ponto acima do dossel e cinco pontos rente ao solo, distribuídos aleatoriamente na unidade experimental (Barbosa et al., 2007).

A densidade populacional de perfilhos basais foi mensurada no pós-corte em dois pontos por parcela, delimitados por armações metálicas de $0,4 \mathrm{~m} \times 0,4 \mathrm{~m}\left(0,16 \mathrm{~m}^{2}\right)$, onde os perfilhos foram contados. A avaliação da dinâmica de perfilhamento ocorreu em um único anel de PVC por parcela, com diâmetro de $30 \mathrm{~cm}$ e fixado por grampos metálicos ao solo. Esses anéis foram alocados no dia da implantação do experimento, não sendo mais movidos ou retirados. Os perfilhos na área delimitada pelo anel foram marcados com fio colorido de uma única cor. Esse procedimento foi repetido no pós-corte de todas as avaliações, sendo escolhido, em cada avaliação, um fio de cor diferente das anteriores para identificar as novas gerações de perfilhos. A partir dos dados, foram calculados: taxa de aparecimento de perfilhos (TApP): $\{[$ (perfilhos novos/total de perfilhos vivos na marcação anterior) x 100]/ dias de rebrotação \} x 30 dias; taxa de mortalidade de perfilhos (TMoP): $\{[$ (perfilhos mortos/total de perfilhos vivos na marcação anterior) x 100]/ dias de rebrotação $\mathrm{x}$ 30 dias; taxa de sobrevivência de perfilhos (TSoP): 1 - TSoP; índice de estabilidade (IE): TSoP (1 + TApP) (Bahmani et al., 2003).

Os dados foram organizados em épocas do ano, de modo que os padrões de respostas fossem semelhantes dentro das épocas. Os valores médios das variáveis respostas em cada época foram calculados pela média ponderada, considerando-se o número de dias do ciclo de rebrotação em cada época. Desse modo, quatro 
estações do ano foram determinadas: Verão 1, de janeiro/2012 a março/2012; Outono, de abril/2012 a junho/2012; Inverno e Início da Primavera (Inv/InPri), de julho/2012 a novembro/2012; Final da Primavera e Verão 2 (FPV2), de dezembro/2012 a março/2013.

Foi utilizado, para análise estatística, o procedimento "PROC MIXED" do programa SAS/STAT ${ }^{\circledR}$ (SAS v9.0, Cary, North Caroline, EUA) versão 9.0, para Windows ${ }^{\circledR}$. Para a escolha da matriz de covariância, utilizou-se o critério de Akaike (Wolfinger, 1993). A interceptação de luz (IL), as alturas residuais no pós-corte, as épocas do ano e suas interações foram consideradas efeitos fixos, enquanto os blocos, efeito aleatório (Littel et al., 1996). Todos os dados foram previamente testados para assegurar as prerrogativas básicas para análise de variância. As médias para os tratamentos foram obtidas por meio do procedimento "LSMEANS", e a comparação foi feita pelo teste de Tukey, com a probabilidade do erro tipo I de $10 \%$.

\section{RESULTADOS E DISCUSSÃO}

A taxa de aparecimento de perfilhos (TApP) foi influenciada pela interação entre a frequência de corte e a estação do ano ( $\mathrm{P}=0,0177)$, de modo que a maior TApP no dossel sob alta frequência de corte (IL ${ }_{95}$ ) ocorreu no Verão 1, em comparação às demais épocas. Nos dosséis manejados com menor frequência de corte $\left(\mathrm{IL}_{\max }\right)$, a TApP foi superior no Verão 1 e no Outono, em comparação às outras épocas (Tab. $1)$.

Tabela 1. Taxa de aparecimento e morte de perfilhos ( $\%$ perfilhos 30 dias $\left.^{-1}\right)$ de capim-piatã nas épocas do ano e submetidos a duas frequências de corte

\begin{tabular}{|c|c|c|c|}
\hline \multirow{2}{*}{ Época do ano } & \multicolumn{2}{|c|}{ Interceptação de luz (\%) } & \multirow{2}{*}{ EPM } \\
\hline & IL & $\mathrm{IL}_{\max }$ & \\
\hline \multicolumn{4}{|c|}{ Taxa de aparecimento de perfilhos } \\
\hline Verão 1 & $59,91 \mathrm{Aa}$ & 47,61 Аа & 3,69 \\
\hline Outono & $24,68 \mathrm{Ba}$ & $38,19 \mathrm{Aa}$ & 3,69 \\
\hline Inv/InPri & $8,58 \mathrm{Ba}$ & $8,26 \mathrm{Ba}$ & 3,69 \\
\hline FPV2 & $22,21 \mathrm{Ba}$ & $22,01 \mathrm{Ba}$ & 3,69 \\
\hline \multicolumn{4}{|c|}{ Taxa de mortalidade de perfilhos } \\
\hline Verão 1 & $15,93 \mathrm{Aa}$ & $17,10 \mathrm{Aa}$ & 3,45 \\
\hline Outono & $6,53 \mathrm{Bb}$ & $10,42 \mathrm{Aa}$ & 0,54 \\
\hline Inv/InPri & $4,08 \mathrm{Ba}$ & $7,23 \mathrm{Ba}$ & 1,15 \\
\hline FPV2 & $19,54 \mathrm{Aa}$ & $15,60 \mathrm{Aa}$ & 1,84 \\
\hline
\end{tabular}

- $\mathrm{IL}_{95}$ : condição em que o dossel intercepta $95 \%$ da luz incidente; $\mathrm{IL}_{\max }$ : condição em que o dossel tem a máxima interceptação da luz incidente. EPM: erro-padrão da média.

Para cada variável, médias seguidas pela mesma letra, maiúscula na coluna e minúscula na linha, não diferem $(\mathrm{P}>0,10)$ pelo teste de Tukey.

A maior TApP no Verão 1 foi resultado da alta disponibilidade de fatores de crescimento, sobretudo água e temperatura (Fig. 1), além da adubação nitrogenada realizada nessa época do ano. Adicionalmente, como o capim-piatã estava em crescimento livre antes do experimento, inclusive durante janeiro e fevereiro, meses em que esse capim concentra seu florescimento (Euclides et al., 2008), pode ter ocorrido expressivo alongamento de colmo e elevação do meristema apical das plantas. Assim, nos primeiros cortes, durante o Verão 1, provavelmente houve eliminação de muitos meristemas apicais, resultando em quebra da dominância apical e estímulo ao perfilhamento (Lemaire e Chapman, 1996). Esse alto perfilhamento também pode ter sido favorecido pela alta incidência de luz na base do dossel (Langer, 1979), após a remoção da forragem velha. tal processo pode ter perdurado até o Outono, no caso dos dosséis manejados com menor frequência de cortes ( $\mathrm{IL}_{\text {máx }}$ ), o que justificaria sua alta TApP (Tab. 1).

A taxa de mortalidade de perfilho (TMoP) também foi influenciada $(\mathrm{P}=0,0892)$ pela interação entre a frequência de corte e a estação do ano (Tab. 1). No Verão1 e no Final da Primavera e Verão 2 (FPV2), houve as maiores TMoP para as duas frequências de corte avaliadas. No Outono, a TMoP também foi alta no dossel cortado com interceptação de luz 
máxima ( $\mathrm{IL}_{\text {máx }}$ ) (Tab. 1). Excetuando-se o Final da Primavera e Verão 2, observou-se que a alta mortalidade esteve associada ao elevado aparecimento de perfilhos (Tab. 1), um processo comum em épocas com clima mais favorável ao crescimento da planta forrageira (Carvalho et al., 2000; Montagner et al., 2012; Morais et al., 2006; Santos et al., 2011). A menor mortalidade de perfilhos e, com efeito, sua maior sobrevivência, em épocas com clima desfavorável ao crescimento, consiste em mecanismo adaptativo para compensar o menor aparecimento de perfilhos (Santos et al., 2011), contribuindo para manter mais estável a população de perfilhos e garantir a perenidade da gramínea. Montagner et al. (2012), quando trabalharam com Panicum maximum cv. Mombaça submetido à lotação intermitente e altura pós-pastejo variável ao longo do ano, também observaram a TMoP sendo menor no inverno e maior na primavera e verão, mesmo resultado para a TApP, o que demonstra a relação entre essas variáveis para manter a estabilidade do pasto.

Embora importante para a persistência da gramínea forrageira, a maior sobrevivência dos perfilhos nas épocas desfavoráveis ao crescimento resulta em um dossel com prevalência de perfilhos com maior idade média (Paiva et al., 2011). Esses perfilhos apresentam piores características estruturais, como menor número de folhas vivas, maior número de folhas senescentes e maior comprimento de colmo (Paiva et al., 2012); bem como menor taxa de crescimento (Paiva et al., 2011). Por outro lado, a alta TMoP no Final da Primavera e Verão 2 pode ser atribuída à maior mortalidade dos perfilhos maduros e velhos, que passaram a ser substituídos por perfilhos mais jovens durante essa época, com clima mais favorável ao crescimento do dossel forrageiro (Fig. 1).

O índice de estabilidade foi influenciado pela interação entre frequência, intensidades de corte e épocas do ano $(\mathrm{P}=0,0199)$. Com exceção dos dosséis manejados com menor frequência $\left(\mathrm{IL}_{\max }\right)$ e altura pós-corte de $15 \mathrm{~cm}$ durante o Verão 1, os demais dosséis apresentaram valores de IE, acima de uma unidade, variando entre 1,001 e 1,016, mas sem diferença estatística. Por esse motivo, apenas os resultados do IE no Verão 1 foram apresentados (Tab. 2). Esse padrão de resposta indica que a densidade populacional de perfilhos foi crescente ao longo do período experimental.

Tabela 2. Índice de estabilidade do capim-piatã submetido a duas frequências e duas alturas no pós-corte na época Verão 1

\begin{tabular}{llll}
\hline $\begin{array}{l}\text { Altura pós-corte } \\
(\mathrm{cm})\end{array}$ & \multicolumn{2}{l}{ Interceptação de luz $(\%)$} & $\mathrm{EPM}$ \\
\cline { 2 - 4 } & $\mathrm{IL} 95$ & $\mathrm{IL}_{\max }$ & 0,002 \\
15 & $1,007 \mathrm{Aa}$ & $0,995 \mathrm{Bb}$ & 0,002 \\
20 & $1,016 \mathrm{Aa}$ & $1,012 \mathrm{Aa}$ & -
\end{tabular}

- $\mathrm{IL}_{95}$ : condição em que o dossel intercepta $95 \%$ da luz incidente; $\mathrm{IL}_{\text {max }}$ : condição em que o dossel tem a máxima interceptação da luz incidente. EPM: erro-padrão da média.

Médias seguidas pela mesma letra, maiúscula na coluna e minúscula na linha, não diferem $(\mathrm{P}>0,10)$ pelo teste de Tukey.

O índice de estabilidade (IE) indica a persistência da população de plantas no pasto e integra as variações das taxas de sobrevivência e de aparecimento de perfilhos no dossel forrageiro. De modo geral, essa persistência é determinada, geneticamente, pela capacidade da planta em substituir os perfilhos mortos, sendo fortemente influenciada pelas condições ambientais, como temperatura, nutrientes, pluviosidade (Mathew et al., 2000), bem como pelo manejo da desfolhação (Barbosa et al., 2011).
Durante o Verão 1, nos dosséis manejados com menor frequência de corte ( $\mathrm{IL}_{\max }$ ) e menor altura pós-corte $(15 \mathrm{~cm})$, a maior mortalidade dos perfilhos pode ser atribuída à eliminação dos meristemas apicais, que resultaram na morte dos perfilhos (Tab. 2). A maior taxa de aparecimento de perfilho no Verão 1, isoladamente, não foi capaz de repor a quantidade de perfilhos mortos nessa época, o que determinou que o IE fosse inferior a uma unidade. Embora o índice de estabilidade nessa ocasião tenha sido menor que 1,0 (0,995, Tab. 2), condição que, se mantida em longo prazo, comprometeria a persistência do pasto, esse manejo da desfolhação fez com que o 
IE fosse maior ou igual a 1,0 nas demais épocas do ano $(1,01 ; 1,001 ; 1,00 ;$ no Outono, Inv/InPri e FPV2, respectivamente), demonstrando uma recuperação na densidade e persistência populacional de perfilhos.

A densidade populacional de perfilhos basais (DPP) variou unicamente entre as épocas do ano $(\mathrm{P}<0,0001)$, sendo menor no Verão 1 , em comparação às demais épocas. Entretanto, a quantidade de perfilhos em uma época foi, numericamente, sempre maior que na precedente (Fig. 2). Isso indica que as taxas de aparecimento de perfilho foram de maior magnitude do que as taxas de mortalidade de perfilho (Tab. 2), independentemente do manejo da desfolhação avaliado.

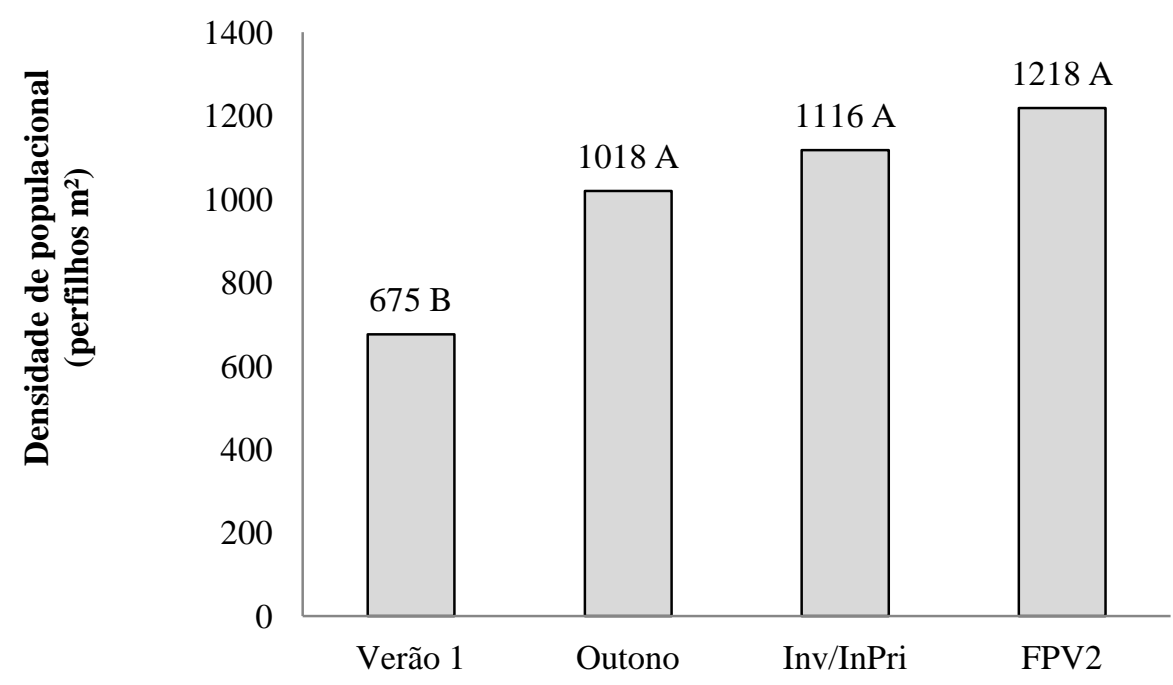

Época do ano

Médias seguidas pela mesma letra maiúsculas não diferem $(\mathrm{P}>0,10)$ pelo teste de Tukey.

Figura 2. Densidade populacional de perfilhos em capim-piatã submetido a regimes de desfolhação intermitente de janeiro de 2012 a março de 2013.

Muitos fatores podem influenciar o perfilhamento em gramíneas forrageiras, entre eles disponibilidade de luz, nutrientes, temperatura, água e estágio de desenvolvimento do dossel (Langer, 1979). Além disso, o manejo da desfolhação também influencia o perfilhamento, pois modifica a quantidade e a qualidade da luz sobre a base do dossel (Barbosa et al., 2007). Nesse contexto, no início do experimento, o corte das plantas que estavam em crescimento livre provavelmente resultou em alta incidência de luz sobre as gemas basais, que foram estimuladas a se desenvolverem em perfilhos (Sbrissia et al., 2010). Ademais, conforme já justificado, a eliminação dos meristemas apicais pela remoção da parte aérea também pode ter anulado a dominância apical nas plantas, o que provavelmente acentuou o perfilhamento ao longo do ano. De fato, do
Verão 1 para o Outono, o aumento da DPP foi de 33,69\%; do Outono para Inv/InPri, e desta época para o FPV2, os incrementos foram relativamente constantes, de $8,78 \%$ e $8,37 \%$, respectivamente.

A densidade populacional de perfilhos é a variável mais flexível do dossel, como meio de manter o índice de área foliar relativamente constante sob condições contrastantes de manejo da desfolhação. Essa variação da densidade populacional de perfilhos caracteriza a plasticidade fenotípica do capim e é importante para otimizar a interceptação de luz, e, com efeito, a fotossíntese e a persistência da planta forrageira aos diferentes manejos da desfolhação (Sbrissia e Silva, 2001). 
Normalmente, a densidade populacional de perfilhos reduz do verão até o inverno (Barbosa et al., 2011; Morais et al., 2006), devido às condições climáticas adversas (pouca chuva, baixa temperatura, redução do fotoperíodo, etc.) ao crescimento vegetal vigentes nessa última estação do ano. Contudo, neste trabalho, esse padrão de resposta não ocorreu. $\mathrm{O}$ incremento da densidade populacional de perfilho, do Verão 1 até o Inverno e Início da Primavera (Fig. 2), quando o clima passou a ser desfavorável ao crescimento da planta (Fig. 1), pode ter ocorrido devido à adaptação do capim-piatã aos regimes de desfolhação avaliados. A mudança da condição de desfolhação dos dosséis, que estavam em crescimento livre, mas passaram a ser cortados com maior frequência com o início do experimento, estimulou o perfilhamento, conforme já discutido, contrabalanceando os efeitos negativos do clima sobre esse processo.

\section{CONCLUSÕES}

As maiores taxas de aparecimento e mortalidade de perfilhos da Brachiaria brizantha cv. Piatã (capim-piatã) ocorrem nas estações com maior disponibilidade de fatores de crescimento. $\mathrm{O}$ capim-piatã sob manejo de desfolhação intermitente pode ser desfolhado com interceptações de luz de $95 \%$ ou máxima, e com alturas pós-corte de 15 ou $20 \mathrm{~cm}$, sem prejudicar o perfilhamento do dossel forrageiro.

\section{REFERÊNCIAS}

ALVARES, C.A.; STAPE, J.L.; SENTELHAS, P.C. et al. Köppen's climate classifivation map for Brazil. Meteorol. Z., v.22, p.711-728, 2013.

BAHMANI, I.; THOM, E.R.; MATTHEW, C. et al. Tiller dynamics of perennial ryegrass cultivars derived from different New Zealand ecotypes: effects of cultivar, season, nitrogen fertilizer, and irrigation. Aust. J. Agricul. Res., v.54, p.803-817, 2003.

BARBOSA R.A.; NASCIMENTO JÚNIOR D.D.; VILELA H.H. et al. Morphogenic and structural characteristics of guinea grass pastures submitted to three frequencies and two defoliation severities. Rev. Bras. Zootec., v.40, p.947-954, 2011
BARBOSA, R.A.; NASCIMENTO JR., D.; EUCLIDES, V.P.B. et al. Capim-tanzânia submetido a combinações entre intensidade e frequência de pastejo. Pesqui. Agropecu. Bras., v.42, p.329-340, 2007.

BULLOCK, J.M. Plant competition and community dynamics. In: HODGSON, J.; ILLIUS, A.W. (Eds.). The ecology and management of grazing systems. Wallingford: CAB International, 1996. chap.3, p.69-100.

CARVALHO, C.A.B.; SILVA, S.C.; SBRISSIA, A.F. et al. Demografia do perfilhamento e taxas de acúmulo de matéria seca em capim 'Tifton 85' sob pastejo. Sci. Agríc., v.57, p.591-600, 2000.

EUCLIDES, V.P.B.; MACEDO, M.C.M.; VALLE, C.B. et al. Produção de forragem e características da estrutura do dossel de cultivares de Brachiaria brizantha sob pastejo. Pesqui. Agropecu. Bras., v.43, p.1805-1812, 2008.

LANGER, R.H.M. How grasses grow. London: 2.ed. London: Edward Arnold, 1979. 66p.

LEMAIRE, G.; CHAPMAN, D. Tissue flows in grazed plant communities. In: HODGSON, J.; ILLIUS, A.W. (Eds.). The ecology and management of grazing systems. [S.1.]: Cab international, 1996. p.3-36.

LITTEL, R.C.; MILLIKEN, G.A.; STROUP, W.W.; WOLFINGER, R.D. SAS system for mixed models. Cary: SAS Institute, 1996. 633p.

MATTHEW, C.; ASSUERO, S.; BLACK, C.K. et al. Tiller dynamies of grazed swards. In: LEMAIRE, G.; HODGSON, J.; MORAIES, A. et al. (Eds.). Grassland ecophysiology and grazing ecology. Wallingford: CABI Publishing, 2000. p.127-150.

MONTAGNER, D.B.; NASCIMENTO JÚNIOR, D.; VILELA, H.H. et al. Tillering dynamics in pastures of guinea grass subjected to grazing severities under intermittent stocking. Rev. Bras. Zootec., v.41,p.544-549. 2012.

MORAIS, R.V.; DA FONSECA, D.M.; DO NASCIMENTO, D. et al. Demografia de perfilhos basilares em pastagem de Brachiaria decumbens adubada com nitrogênio. Re Rev. Bras. Zootec., v.35, p.380-388, 2006 
PAIVA A.J.; SILVA S.C.; PEREIRA L.E.T. et al. Structural characteristics of tiller age categories of continuously stocked marandu palisade grass swards fertilized with nitrogen. Rev. Bras. Zootec., v.41, p.24-29, 2012.

PAIVA, A.J.; SILVA, S.C.; PEREIRA, L.E.T. et al. Morphogenesis on age categories of tillers in marandu palisadegrass. Sci. Agric., v.68, p.626631,2011

RIBEIRO, A.C.; GUIMARÃES, P.T.G.; ALVES, V.H. (Eds.). Recomendações para o uso de corretivos e fertilizantes em Minas Gerais: $5^{\mathrm{a}}$ Aproximação. 5.ed. Viçosa, MG: UFV, 1999. 359p.

SANTOS M.E.R.; MIRANDA, D.; GOMES, V.M. et al. Capim-braquiária sob lotação contínua e com altura única ou variável durante as estações do ano: dinâmica do perfilhamento. Rev. Bras. Zootec., v.40, p.2332-2339, 2011
SBRISSIA, A.F.; SILVA, S.C. Compensação tamanho/densidade populacional de perfilhos em pastos de capim-marandu. Rev. Bras. Zootec., v.37, p.35-47, 2008.

SBRISSIA, A.F.; SILVA, S.C. O ecossistema de pastagens e a produção animal. In: REUNIÃO ANUAL DA SOCIDADE BRASILEIRA DE ZOOTECNIA, 38, 2001, Piracicaba. Anais... Piracicaba, SP: Sociedade Brasileira de Zootecnia, 2001. p.731-754.

SBRISSIA, A.F.; SILVA, S.C.; SARMENTO, D.O.L. et al. Tillering dynamics in palisadegrass swards continuously stocked by cattle. Plant Ecol., v.206, p.349-359, 2010.

SISTEMA brasileiro de classificação de solos. Brasília: Embrapa, 1999. 412p. (Produção de Informação).

WOLFINGER, R.D. Covariance structure selection in general mixed models. Commun. Stat. Simul. Comput., v.22, p.1079-1106, 1993. 